\title{
Magnesium: a versatile drug for anesthesiologists
}

\author{
Sang-Hwan Do \\ Department of Anesthesiology and Pain Medicine, Seoul National University Bundang Hospital, Seongnam, Korea
}

Magnesium sulfate has been used in preeclampsia patients in order to prevent seizure. It is also used for the treatment of arrhythmia and asthma and as an anesthetic adjunct in patients undergoing surgery for pheochromocytoma. However, its potentiating effects on perioperative analgesia and muscle relaxation have drawn attention recently. These characteristics of magnesium (anesthetic- and analgesic-sparing effect) enable anesthesiologists to reduce the use of anesthetics during surgery and the use of analgesics after surgery. Magnesium sulfate has a high therapeutic index and cost-effectiveness. Considering these diverse characteristics useful for anesthesia, appropriate use of magnesium sulfate would improve surgical outcome and patients' satisfaction. (Korean J Anesthesiol 2013; 65: 4-8)

Key Words: Analgesia, Magnesium, Magnesium sulfate, Muscle relaxation.

\section{Introduction}

Magnesium plays a critical role in a variety of physiologic processes. Ever since the study of magnesium sulfate in clinical anesthesia beginning in 1996, magnesium has drawn attention in the field of anesthesia and pain medicine [1]. Recently, numerous clinical studies, review articles and meta-analyses have been published worldwide [2-8]. In this review article, the efficacy of magnesium is described in terms of analgesia and muscle relaxation in surgical patients.

\section{Physiology and Pharmacology}

Magnesium is the fourth most common cation in the body and has a key role in hundreds of physiologic processes [9]. Among the numerous actions of magnesium, the blockade of
$\mathrm{N}$-methyl-D-aspartate (NMDA) receptor and calcium channel has an important meaning to anesthesia. The normal range of magnesium in plasma is $0.7-1.1 \mathrm{mmol} / \mathrm{L}(1.4-2.2 \mathrm{mEq} / \mathrm{L})$. Hypomagnesemia can occur frequently, especially after surgery such as abdominal, orthopedic and cardiac operation. From the report of Aglio et al. [10], the incidence of hypomagnesemia was $19.2 \%$ before cardiac surgery, peaked to $71 \%$ immediately after surgery, and subsided slightly to $65.6 \% 24 \mathrm{~h}$ after then.

Hypermagnesia occurs rarely in clinical medicine unless the renal function of the patient is compromised. If the plasma concentration of magnesium reaches 4-5 $\mathrm{mmol} / \mathrm{L}$, toxic symptoms such as loss of deep tendon reflex and dizziness can occur. At higher concentrations, respiratory arrest $(>6 \mathrm{mmol} / \mathrm{L})$ or cardiac arrest ( $>8 \mathrm{mmol} / \mathrm{L})$ can develop. Magnesium sulfate $\left(\mathrm{MgSO}_{4}\right)$ and magnesium chloride $\left(\mathrm{MgCl}_{2}\right)$ are both available; however, the latter is used mostly in research laboratories [9].

Received: April 8, 2013. Accepted: April 15, 2013.

Corresponding author: Sang-Hwan Do, M.D., Department of Anesthesiology and Pain Medicine, Seoul National University Bundang Hospital, 166, Gumi-ro, Bundang-gu, Seongnam 463-707, Korea. Tel: 82-31-787-7501, Fax: 82-31-787-4063, E-mail: shdo@snu.ac.kr

(c) This is an open-access article distributed under the terms of the Creative Commons Attribution Non-Commercial License (http:// creativecommons.org/licenses/by-nc/3.0/), which permits unrestricted non-commercial use, distribution, and reproduction in any medium, provided the original work is properly cited. 


\section{Analgesia in Surgical Patients}

Although magnesium is not a primary analgesic in itself, it enhances the analgesic actions of more established analgesics as an adjuvant agent. The role of magnesium for perioperative analgesia has been investigated by many authors. Magnesium sulfate has been reported to be effective in perioperative pain treatment and in blunting somatic, autonomic and endocrine reflexes provoked by noxious stimuli [11-13]. Usual regimens of magnesium sulfate administration were a loading dose of $30-50 \mathrm{mg} / \mathrm{kg}$ followed by a maintenance dose of $6-20 \mathrm{mg} / \mathrm{kg} / \mathrm{h}$ (continuous infusion) until the end of surgery. However, a single bolus of magnesium without maintenance infusion was also effective for postoperative analgesia in some previous reports.

When magnesium was used intraoperatively, many researchers reported that it reduced the requirement for anesthetics and/or muscle relaxants. In terms of postoperative analgesia, intraoperative magnesium during surgery can reduce opioid consumption in the first $24 \mathrm{~h}$ postoperatively, and to a lesser extent, pain scores. Ryu et al. [14] compared magnesium sulfate and remifentanil during middle ear surgery. In this study, either drug when combined with sevoflurane provided adequate level of hypotensive anesthesia, however, the magnesium group had more favorable postoperative courses showing better analgesia and less shivering and nausea/vomiting after surgery. In addition, sevoflurane was required less to maintain surgical anesthesia in patients receiving magnesium sulfate than those receiving remifentanil.

Magnesium sulfate, as an analgesic adjunct, can also be useful in patients receiving total intravenous analgesia (TIVA). Seyhan et al. [15] reported that magnesium sulfate reduced propofol, atracurium and postoperative morphine consumption in gynecologic surgical patients. In another study employing gynecologic patients undergoing laparotomy under TIVA, pain scores, analgesic consumption and shivering incidents were lower in the magnesium group compared with control, and it was concluded that magnesium sulfate improved the quality of postoperative analgesia during TIVA. Gupta et al. [16] also reported that magnesium reduced the requirements for propofol, rocuronium and fentanyl in spinal surgical patients. It is conceivable that the intraoperative use of magnesium sulfate may mitigate remifentanil-induced hyperalgesia in patients receiving TIVA.

The usefulness of magnesium for postoperative analgesia is not limited to general anesthesia. Recent studied suggested that magnesium sulfate can play a beneficial role also in spinal anesthesia when administered via both intravenous or intrathecal route. Magnesium can prevent the induction of central sensitization from peripheral nociceptive stimuli at the spinal action site by blocking NMDA receptors in a voltage-dependent manner [17]. With the same mechanism, when small doses of magnesium sulfate was added to local anesthetics for spinal anesthesia, the duration of anesthesia was prolonged, postoperative analgesic requirement was reduced and the side effects of high doses of local anesthetics and opioids were decreased. In animal studies, when magnesium sulfate was co-administered during spinal anesthesia, it significantly potentiated morphine analgesia in rats with or without surgical incision [18]. In another experimental murine model, the intrathecal injection of magnesium sulfate produced a state of general sedation and spinal anesthesia, lasting about $1 \mathrm{~h}$ and these effects were reversed after $6 \mathrm{~h}$ without neurotoxicity [19]. Clinical studies also showed that intrathecal magnesium sulfate added to fentanyl prolonged labor analgesia without any increase in side effects [20,21]. In addition, i.v. infusion of magnesium sulfate during spinal anesthesia was reported to improve postoperative analgesia and to reduce cumulative consumption of analgesics after total hip replacement arthroplsaty [22]. Postoperative i.v. magnesium sulfate infusion also increased the time to analgesic need and reduced the total consumption of analgesics after spinal anesthesia [23].

Whereas intrathecal magnesium sulfate has been studied in many studies, there are few data on the effect of epidural magnesium sulfate. Magnesium sulfate added to lidocaine which was into the caudal epidural space prolonged analgesia compared with plain lidocaine in cattle [24]. Arcioni et al. [25] investigated whether there were any synergistic interactions between intrathecal and epidural administration of magnesium sulfate in terms of postoperative analgesia in patients undergoing orthopedic surgery. The results suggested that combined intrathecal and epidural magnesium sulfate administration significantly reduces postoperative analgesic requirements.

Not all of the investigations have reported postoperative analgesic effect of magnesium sulfate. Perioperative i.v. magnesium administration did not reduce postoperative pain and analgesic consumption in patients undergoing abdominal hysterectomy [26] and cesarean delivery [27]. Interestingly, epidural analgesia was used after surgery in the above studies, and thus, it is possible that superior analgesic efficacy of epidural analgesia over intravenous analgesia might have masked the analgesia-potentiating effect of magnesium sulfate. A recent report by Tramer and Glynn [28] also showed that the pretreatment of magnesium sulfate in patients undergoing ambulatory ilioinguinal hernia repair or varicose vein operations has no effect on postoperative analgesia for the first three postoperative days. However, in this study, a single dose (4 g) of magnesium sulfate was used instead of the loading dose plus continuous infusion.

Intraoperative use of magnesium sulfate can be associated with decreased incidences of nausea and vomiting after surgery $[14,29]$, which could have been due to the lower consumption 
of volatile anesthetic (sevoflurane) [14,30] rather than any antiemetic effect of magnesium sulfate. Nevertherless, because nausea/vomiting is one of the most common and distressing complications after surgery, this effect is helpful for surgical patients, because it could be used to benefit, for example, patients undergoing ambulatory surgery. In addition, perioperative i.v. administration of magnesium sulfate has another advantageous effect, as it decreases the incidence of shivering by up to $70-90 \%$ $[14,28,29]$. Due to the fact that shivering is a leading cause of postoperative discomfort and increases oxygen consumption [31], the prevention of shivering is one of the most obvious benefits of magnesium sulfate use in surgical patients.

When mixed with local anesthetic, magnesium sulfate may also show beneficial effects in intravenous regional anesthesia (Bier block). Turan et al. [32] reported that when magnesium was added to lidocaine for Bier block, the quality of anesthesia and analgesia was improved. Specifically, the onset times of the sensory and motor blocks were shorter and postoperative analgesia was better with magnesium. However, in this previous study, recovery after Bier block was prolonged in the magnesium group. In contrast, magnesium sulfate infusion during general anesthesia has not been found to delay recovery from anesthesia in most investigations [29,33,34]. Another consideration during magnesium sulfate administration is that it may cause cardiovascular depression by acting as a calcium channel blocker. The consequent inhibition of catecholamine release reduces plasma epinephrine and norepinephrine concentrations after endotracheal intubation, and therefore reduces hypertensive responses during anesthesia induction [35]. Thus, magnesium sulfate should be used with caution in hypovolemic patients and in those with limited cardiac capacity. In addition, slow administration $(>10 \mathrm{~min}$ ) of the loading dose of magnesium sulfate may minimize cardiovascular side effects, such as hypotension and bradycardia.

\section{Muscle Relaxation}

Magnesium acts as a calcium channel blocker at presynaptic nerve terminals and decreases acetylcholine release at the motor endplate, which diminishes muscle fiber excitability and reduces the amplitude of endplate potential, resulting in the potentiation of a neuromuscular blockade by nondepolarizing neuromuscular blocker [36]. Some authors have focused on the direct enhancing effects of magnesium on the neuromuscular blockade [37-40]. In contrast, others concluded that a perioperative adjuvant magnesium sulfate administration reduced requirements for nondepolarizing neuromuscular blockers [15,29,33,41-43].

Potentiation of muscle relaxation by magnesium sulfate can have diverse clinical implications. First of all, magnesium sulfate can be used as an adjuvant to tracheal intubation. Until recently, when used during the induction of general anesthesia, magnesium has been highlighted on its efficacy to attenuate cardiovascular responses associated with tracheal intubation [44,45]. In addition, Kim et al. [46] reported that magnesium sulfate, when combined with rocuronium priming, improved rapid-sequence intubating conditions, compared with either magnesium sulfate or priming used alone.

In the operating room, the patient sometimes exhibits resistance to nondepolarizing muscle relaxants, which may result from a drug or a disease of the patient. In such cases, magnesium sulfate can be used effectively. In patients undergoing craniotomy, valproic acid is often prescribed before operation in order to prevent postoperative seizure. Kim et al. [47] reported that valproic acid decreases rocuronium duration resulting in increase in its requirement; however, magnesium sulfate administration attenuated this increase. Children with cerebral palsy show resistance to nondepolarizing neuromuscular blocking agents [48]. When magnesium sulfate was administered during operation in children with cerebral palsy, the rocuronium requirement was significantly decreased and postoperative opioid consumption was also decreased [41].

Magnesium sulfate can also be helpful when succinylcholine is used for tracheal intubation. Magnesium may prevent hyperkalemia produced by succinylcholine [49]. Sakuraba et al. [50] reported that pretreatment with magnesium sulfate is associated with less fasciculation induced by succinylcholine. However, magnesium was reported not to influence the clinical course of succinylcholine-induced malignant hyperthermia [51].

At the recovery phase of spinal anesthesia, the motor block recovers ahead of the sensory block. When additional muscle relaxation (motor block) is requested by the surgeon while suturing the surgical wound, magnesium sulfate can be used efficaciously.

\section{Conclusion}

Magnesium sulfate is an old drug, but has multiple characteristics which are very useful for anesthesiologists. When it is used appropriately to enhance analgesia and muscle relaxation in surgical patients, it can contribute to improvement in the outcome of surgical patients. 


\section{References}

1. Tramer MR, Schneider J, Marti RA, Rifat K. Role of magnesium sulfate in postoperative analgesia. Anesthesiology 1996; 84: 340-7.

2. Albrecht E, Kirkham KR, Liu SS, Brull R. Peri-operative intravenous administration of magnesium sulphate and postoperative pain: a metaanalysis. Anaesthesia 2013; 68: 79-90.

3. Do SH. Usefulness of magnesium sulfate in the field of anesthesia and pain medicine. Anesth Pain Med 2008; 3: 157-61.

4. Dube L, Granry JC. The therapeutic use of magnesium in anesthesiology, intensive care and emergency medicine: a review. Can J Anaesth 2003; 50: 732-46.

5. Herroeder S, Schonherr ME, De Hert SG, Hollmann MW. Magnesium--essentials for anesthesiologists. Anesthesiology 2011; 114: 971-93.

6. Morrison AP, Hunter JM, Halpern SH, Banerjee A. Effect of intrathecal magnesium in the presence or absence of local anaesthetic with and without lipophilic opioids: a systematic review and meta-analysis. Br J Anaesth 2013; 110: 702-12.

7. Na HS, Ryu JH, Do SH. Magnesium in the central nervous system. Adelaide, University of Adelaide Press. 2011, pp 157-65.

8. Soave PM, Conti G, Costa R, Arcangeli A. Magnesium and anaesthesia. Curr Drug Targets 2009; 10: 734-43.

9. Fawcett WJ, Haxby EJ, Male DA. Magnesium: physiology and pharmacology. Br J Anaesth 1999; 83: 302-20.

10. Aglio LS, Stanford GG, Maddi R, Boyd JL 3rd, Nussbaum S, Chernow B. Hypomagnesemia is common following cardiac surgery. J Cardiothorac Vasc Anesth 1991; 5: 201-8.

11. Kara H, Sahin N, Ulusan V, Aydogdu T. Magnesium infusion reduces perioperative pain. Eur J Anaesthesiol 2002; 19: 52-6.

12. Koinig H, Wallner T, Marhofer P, Andel H, Horauf K, Mayer N. Magnesium sulfate reduces intra- and postoperative analgesic requirements. Anesth Analg 1998; 87: 206-10.

13. Levaux Ch, Bonhomme V, Dewandre PY, Brichant JF, Hans P. Effect of intra-operative magnesium sulphate on pain relief and patient comfort after major lumbar orthopaedic surgery. Anaesthesia 2003; 58: 131-5.

14. Ryu JH, Sohn IS, Do SH. Controlled hypotension for middle ear surgery: a comparison between remifentanil and magnesium sulphate. Br J Anaesth 2009; 103: 490-5.

15. Seyhan TO, Tugrul M, Sungur MO, Kayacan S, Telci L, Pembeci K, et al. Effects of three different dose regimens of magnesium on propofol requirements, haemodynamic variables and postoperative pain relief in gynaecological surgery. Br J Anaesth 2006; 96: 247-52.

16. Gupta K, Vohra V, Sood J. The role of magnesium as an adjuvant during general anaesthesia. Anaesthesia 2006; 61: 1058-63.

17. Woolf CJ, Thompson SW. The induction and maintenance of central sensitization is dependent on N-methyl-D-aspartic acid receptor activation; implications for the treatment of post-injury pain hypersensitivity states. Pain 1991; 44: 293-9.

18. Kroin JS, McCarthy RJ, Von Roenn N, Schwab B, Tuman KJ, Ivankovich AD. Magnesium sulfate potentiates morphine antinociception at the spinal level. Anesth Analg 2000; 90: 913-7.

19. Bahar M, Chanimov M, Grinspun E, Koifman I, Cohen ML. Spinal anaesthesia induced by intrathecal magnesium sulphate. Anaesthesia 1996; 51: 627-33.

20. Buvanendran A, McCarthy RJ, Kroin JS, Leong W, Perry P, Tuman KJ. Intrathecal magnesium prolongs fentanyl analgesia: a prospective, randomized, controlled trial. Anesth Analg 2002; 95: 661-6.

21. Ozalevli M, Cetin TO, Unlugenc H, Guler T, Isik G. The effect of adding intrathecal magnesium sulphate to bupivacaine-fentanyl spinal anaesthesia. Acta Anaesthesiol Scand 2005; 49: 1514-9.

22. Hwang JY, Na HS, Jeon YT, Ro YJ, Kim CS, Do SH. I.V. infusion of magnesium sulphate during spinal anaesthesia improves postoperative analgesia. Br J Anaesth 2010; 104: 89-93.

23. Apan A, Buyukkocak U, Ozcan S, Sari E, Basar H. Postoperative magnesium sulphate infusion reduces analgesic requirements in spinal anaesthesia. Eur J Anaesthesiol 2004; 21: 766-9.

24. Dehghani SN, Bigham AS. Comparison of caudal epidural anesthesia by use of lidocaine versus a lidocaine-magnesium sulfate combination in cattle. Am J Vet Res 2009; 70: 194-7.

25. Arcioni R, Palmisani S, Tigano S, Santorsola C, Sauli V, Romano S, et al. Combined intrathecal and epidural magnesium sulfate supplementation of spinal anesthesia to reduce post-operative analgesic requirements: a prospective, randomized, double-blind, controlled trial in patients undergoing major orthopedic surgery. Acta Anaesthesiol Scand 2007; 51: 482-9.

26. Ko SH, Lim HR, Kim DC, Han YJ, Choe H, Song HS. Magnesium sulfate does not reduce postoperative analgesic requirements. Anesthesiology 2001; 95: 640-6.

27. Paech MJ, Magann EF, Doherty DA, Verity LJ, Newnham JP. Does magnesium sulfate reduce the short- and long-term requirements for pain relief after caesarean delivery? A double-blind placebo-controlled trial. Am J Obstet Gynecol 2006; 194: 1596-602.

28. Tramer MR, Glynn CJ. An evaluation of a single dose of magnesium to supplement analgesia after ambulatory surgery: randomized controlled trial. Anesth Analg 2007; 104: 1374-9.

29. Ryu JH, Kang MH, Park KS, Do SH. Effects of magnesium sulphate on intraoperative anaesthetic requirements and postoperative analgesia in gynaecology patients receiving total intravenous anaesthesia. Br J Anaesth 2008; 100: 397-403.

30. Apfel CC, Kranke P, Katz MH, Goepfert C, Papenfuss T, Rauch S, et al. Volatile anaesthetics may be the main cause of early but not delayed postoperative vomiting: a randomized controlled trial of factorial design. Br J Anaesth 2002; 88: 659-68. 
31. Alfonsi P. Postanaesthetic shivering: epidemiology, pathophysiology, and approaches to prevention and management. Drugs 2001; 61: 2193-205.

32. Turan A, Memiş D, Karamanlioğlu B, Güler T, Pamukçu Z. Intravenous regional anesthesia using lidocaine and magnesium. Anesth Analg 2005; 100: 1189-92.

33. Lee DH, Kwon IC. Magnesium sulphate has beneficial effects as an adjuvant during general anaesthesia for Caesarean section. Br J Anaesth 2009; 103: 861-6.

34. Ozcan PE, Tugrul S, Senturk NM, Uludag E, Cakar N, Telci L, et al. Role of magnesium sulfate in postoperative pain management for patients undergoing thoracotomy. J Cardiothorac Vasc Anesth 2007; 21: 827-31.

35. James MF, Beer RE, Esser JD. Intravenous magnesium sulfate inhibits catecholamine release associated with tracheal intubation. Anesth Analg 1989; 68: $772-6$.

36. Fisher DM. Clinical pharmacology of neuromuscular blocking agents. Am J Health Syst Pharm 1999; 56(11 Suppl 1): S4-9.

37. Fuchs-Buder T, Tassonyi E. Magnesium sulphate enhances residual neuromuscular block induced by vecuronium. Br J Anaesth 1996; 76: 565-6.

38. Fuchs-Buder T, Wilder-Smith OH, Borgeat A, Tassonyi E. Interaction of magnesium sulphate with vecuronium-induced neuromuscular block. Br J Anaesth 1995; 74: 405-9.

39. Kussman B, Shorten G, Uppington J, Comunale ME. Administration of magnesium sulphate before rocuronium: effects on speed of onset and duration of neuromuscular block. Br J Anaesth 1997; 79: 122-4.

40. Ross RM, Baker T. An effect of magnesium on neuromuscular function in parturients. J Clin Anesth 1996; 8: 202-4.

41. Na HS, Lee JH, Hwang JY, Ryu JH, Han SH, Jeon YT, et al. Effects of magnesium sulphate on intraoperative neuromuscular blocking agent requirements and postoperative analgesia in children with cerebral palsy. Br J Anaesth 2010; 104: 344-50.

42. Oguzhan N, Gunday I, Turan A. Effect of magnesium sulfate infusion on sevoflurane consumption, hemodynamics, and perioperative opioid consumption in lumbar disc surgery. J Opioid Manag 2008; 4: 105-10.

43. Telci L, Esen F, Akcora D, Erden T, Canbolat AT, Akpir K. Evaluation of effects of magnesium sulphate in reducing intraoperative anaesthetic requirements. Br J Anaesth 2002; 89: 594-8.

44. Panda NB, Bharti N, Prasad S. Minimal effective dose of magnesium sulfate for attenuation of intubation response in hypertensive patients. J Clin Anesth 2013; 25: 92-7.

45. Shin YH, Choi SJ, Jeong HY, Kim MH. Evaluation of dose effects of magnesium sulfate on rocuronium injection pain and hemodynamic changes by laryngoscopy and endotracheal intubation. Korean J Anesthesiol 2011; 60: 329-33.

46. Kim MH, Oh AY, Jeon YT, Hwang JW, Do SH. A randomised controlled trial comparing rocuronium priming, magnesium pre-treatment and a combination of the two methods. Anaesthesia 2012; 67: 748-54.

47. Kim MH, Hwang JW, Jeon YT, Do SH. Effects of valproic acid and magnesium sulphate on rocuronium requirement in patients undergoing craniotomy for cerebrovascular surgery. Br J Anaesth 2012; 109: 407-12.

48. Moorthy SS, Krishna G, Dierdorf SF. Resistance to vecuronium in patients with cerebral palsy. Anesth Analg 1991; 73: 275-7.

49. Yap LC, Ho RT, Jawan B, Lee JH. Effects of magnesium sulfate pretreatment on succinylcholine-facilitated tracheal intubation. Acta Anaesthesiol Sin 1994; 32: 45-50.

50. Sakuraba S, Serita R, Kosugi S, Eriksson LI, Lindahl SG, Takeda J. Pretreatment with magnesium sulphate is associated with less succinylcholineinduced fasciculation and subsequent tracheal intubation-induced hemodynamic changes than precurarization with vecuronium during rapid sequence induction. Acta Anaesthesiol Belg 2006; 57: 253-7.

51. Metterlein T, Schuster F, Kranke P, Hager M, Roewer N, Anetseder M. Magnesium does not influence the clinical course of succinylcholine-induced malignant hyperthermia. Anesth Analg 2011; 112: 1174-8. 